\title{
Navigating Cross-Cultural Research in Qualitative Inquiry
}

\author{
Ramodungoane Tabane \\ Dept of Psychology of Education \\ College of Education, University of South Africa \\ Tabanri@unisa.ac.za
}

\section{Doi:10.5901/mjss.2014.v5n3p599}

\begin{abstract}
Cross-cultural study requests that researchers should be alert of the makeup and the organisation of the research itself. The researchers should be mindful of their research interest and strive to maximise the data collected and analysed. The involvement of experts who are from the culture or indigenous group being studied enriches data and benefits research. It was important in this study to involve the community under study to form part of the research team and to learn from them about the ins and outs of their culture while trying to establish the phenomenon and focus of the study. It was further important for the researchers to demarcate their study and do away with their academic pre-established categories for organising and interpreting data but rather stay at a distance and learn from the culture under study.
\end{abstract}

Keywords: culture; cross-cultural; indigenous; psychology; methodological considerations; qualitative research

\section{Introduction}

Conducting a cross-cultural research as an inquiry into qualitative research should be distinguished from other research studies and approaches. Cross-cultural researches and studies are employed because the unique elements of eticsemics of the study are presented. Researchers depending on their cultural standing can be regarded as sojourners in the etics senses of cross-cultural studies and regarded as "culture general" or "outside" regarding the phenomena and/or population involved in the study. The opposite thus is that the research population, for instance, or the phenomena of interest presents the emics of cross-cultural studies and these are regarded in most cases as "culture specific" or "indigenous" or "inside" to the cross-cultural study.

Various research studies (Swisher, 1998; Smith, 1999; Lomawaima, 2000; Mihesuah, 2003, 2004; Mutua \& Swadener, 2004; Wilson, 2004, 2008; Webster \& John, 2010) have been conducted on the effect of research on the indigenous participants. This research article reports on the impact that good cross-cultural research practice might have in qualitative inquiry. It presents the research methodology of a study commissioned by the USAID and undertaken under the auspices of a healthcare solutions company, BroadReach Healthcare (BRHC), which culminated in a report entitled, "An exploratory study of how Traditional Health Practices (THP) in South Africa communicate the concepts of disease risk and prevention to their patients" (Broad Reach Health Care, Tabane, Mbele-Khama \& Dlamini 2012). The Traditional Health Practitioners (THPs) are regarded as the custodians of the indigenous knowledge system and their role is pivotal as future research partners or collaborators. It was thus important for this research to seek a research methodology that would preserve the cultural specifics of the study while maximising authentic data collection. Thus, the research team had to include the researchers who represented the emics of the phenomena of study and in this instance; it was the traditional knowledge of the THPs.

THPs represent the first line of healthcare for many people in Sub-Saharan Africa. The understanding of traditional messages and treatment around disease or any other aspect of this field is thus important because traditional health practising can be regarded as a cornerstone of African tradition and culture and represents a sensitive area for researchers who wish to explore it and its impact on health-seeking behaviour.

Like most of the indigenous population in research, THPs also do not easily allow sojourners and/or outsiders' entry in their fields and this is so because of mistrust (Webster \& John, 2010) that has been happening over the years. The relevance of conducting researches in the indigenous fields like THPs is now becoming more prominent especially in Sub-Saharan regions. This is a result of people becoming open in practising their indigenous beliefs in addressing their day-to-day issues including both physical and mental health.

According to Kagitçibaşi and Berry (1989) the indigenisation of psychology in the Third World is gaining 
momentum and it stresses the need for a problem-centred, not theory-driven approach. Thus, gaining an understanding of how the THPs through their practices address issues of health was one of the key research objectives of this study. It is essential that these practices are authentically understood in order to address and appropriately target health messages and interventions for behavioural change. Thus researchers in cross-cultural studies need to develop cultural competency about the phenomena being studied, according to Pope-Davis, Toporek, Ortega-Villalobos, Ligiéro, BrittanPowell, Liu, Bashshur, Codrington, and Liang (2002). This is important because:

\begin{abstract}
the underlying assumption has been that if a [researcher] is culturally competent, the [researcher] will be able to provide the most effective service through the establishment of rapport, appropriate interventions, and culturally appropriate treatment (Pope-Davis et al, 2002:356).
\end{abstract}

\title{
2. Cross-Cultural Research Methodology Considerations
}

Culture is one of the concepts defined differently by various authors and Ponterotto, Casas, Suzuki, and Alexander (1995) in ḰEgisdóttir, Gerstein, and Çinarbaş, (2008) concluded that for most scholars, culture is a learned system of meaning and behaviour that is passed from one generation to the next. Studying this concept employs researchers to use different approaches. In the study of cross-culture the implications are that there are meanings, for instance, that are learned and passed from one context to the next (etics) and most importantly there are elements that might be foreign to this culture and they have equal influence on that particular culture (emics). Thus the study of cross-culture and the research considerations of the constructs that defines it are important.

Various research involving cross-cultural studies are undertaken as collaborations between the researchers, as outsiders and the indigenous populations, as the custodians of the phenomena under study. The indigenous population in most cases do not readily allow outsiders entry in their space and if granted it is with conditions. According to Webster and John (2010:175) "even those indigenous communities that allow entry into the field often approach these research "collaborations' with distrust or apprehension". Thus, a deliberate decision to devise a cross-cultural research method that will grant access to the phenomena of study was made.

In this research it was decided that since the phenomena of study is around the practices of THPs, it will be of benefit to the study to include the expertise of the THPs who will be advisors, guides and regarded as experts in the study.

\section{Recruitment of Research Experts}

In cross-cultural research the thin line that describes what is etics and what is the emics of the research is paramount. Therefore it is paramount to distinguish practices in the research that can be regarded as outside influence, thus the etics, and those that can be regarded as having specific insider influence, thus the emics. The research team consisted of researchers who were not THPs (etics). Thus, to avoid potential challenges with accessing data and to address these cross-cultural methodological issues it was devised to acquire the skills of THPs (emics) who became expert advisors on the project. The interest in access was regarded broadly and not only to enter into the research site, but also to address, according to ǼEgisdóttir et al (2008), cross-cultural methodological and design concerns such as equivalence, bias and translations.

Two THPs were invited to become part of the research team that was made up of a black male - principal investigator; white female - project leader/researcher and Indian female - project administrator/researcher, because of their involvement and their status in the THP communities. The first THP member (black, female - researcher) was a researcher by profession, actively involved in the THP issues including training THPS in their practice and championed them on the political arena. The second THP member (black, male - researcher) was involved in various community projects including training the THPs and also was employed at some point with the Department of Health. Thus it was a strategic and conscious plan to involve the expert THPs because a research team only made up of non-THPs would have raised ethical and methodological issues in cross-cultural research. Personal attributes of the researchers need to be taken into consideration during a cross-cultural study, hence the mention for instance in this case, of race and gender. This was done so that a research context is clarified in terms of the insider and outsider position of the researchers in relation to participants and to the phenomena under study, for instance the potential of losing intricacies of data due to culture-specific nuances.

In inviting the two THPs, a further consideration was that they must be individuals who were respected in the field of THP and they had to meet criteria agreed with the research team. The expert THPs firstly have to fall under one or 
more recognised Traditional Health Practitioners Act No. 22 of 2007 categories, namely, diviners, herbalists, traditional birth attendants and traditional surgeons. Secondly, the THPs' experience was taken into consideration. They should have successfully graduated new THP entrants and they at least should have been training THPs for 10 years.

The expert advisors were recruited for their knowledge of the THP practices and their knowledge of the topic and their focus on the bigger study. Thus, as a result of their invaluable wealth of THP knowledge and practices, they assisted with the conceptualisation of the qualitative research methodology; facilitated access to the research site and ensured that in the provinces where the main study was conducted, there was an identified contact person. Furthermore, they also assisted with the designing of the research tool, the questionnaire used to collect data as well as the individual interview protocol used in the study. This was a crucial role as it guaranteed equivalence, bias and translations ( ÆÉgisdóttir et al 2008) as cross-cultural methodological and design concerns. The experts also coached and mentored the non-THP team members on what are regarded as acceptable behaviour in and around the traditional practices.

One other important role that the expert THPs played was to be critical partners in searching, screening and identifying THPs who will conduct the focus groups as moderators and also conduct the individual interviews with the participants. They also had to scrutinise and ensure that the THPs who participated in the study met the requirements of the study, especially ensuring that all four categories of THPs as recognised by the Traditional Health Practitioners Act No. 22 of 2007 were represented. Furthermore, as non-THPs have no expertise in their practices, the expert THPs had to validate the credibility of the THP participants so that unauthentic THPs did not slip in - as this could have had negative consequences for the credibility of their entire study.

Webster and John (2010) refer to the concept of power and in particular the power relationship in research in general and specifically in cross-cultural research. They point out the imbalance of power between the academic welldominant researches oppressing the indigenous and the less researched areas.

Thus, our deliberate and conscious efforts to utilise both Indigenous [sic] and western theoretical and methodological frameworks often prompted ethical concerns about power relationships that might serve to subordinate Indigenous [sic] ....epistemology, methodology and representations of knowledge to the established western academic traditions. (Webster and John, 2010:176).

It was also deliberate to be sensitive and comprise a research team of our make so that the etics-emics of the cross-cultural research are maintained. Gee (2007) in Webster and John (2010:176) alerts us to the importance of a research team makeup because in their research into their own multiple-situated identities (e.g. non-native, Alaska native, women academics, community member, non-community member, etc.), they also began to question the notion of insider/outsider. Furthermore, they questioned their own roles in terms of the dominant academic discourses historically privileged in conducting research on or even with indigenous peoples.

Thus, during this research we constantly conducted member checking in terms of the makeup of the focus groups and the interview situation. The non-THP researchers were kept at a distance and their roles were non-participatory observers while the THP research team members took a lead.

\section{Data Collection}

The focus group and interviews were conducted, recorded electronically and transcribed by the THPs. This was done so that information, subtle messages and the rich contexts of the responses are not lost in translation, which could have been at risk when done by non-THPs. This was undertaken as measures to ensure trustworthiness and authenticity of the data collected and to be analysed.

\section{Data Analysis}

A qualitative data analysis software called Nvivo9 was used to thematically analyse text from the study. The research team firstly had to develop themes from the objective of the study. Secondly, the expert THPs had to sensitise and advise the team on themes that are of THP nature and significance, thus developing such as themes for analysis. Transcripts were coded into broad categories and then supplemented by more coding sessions with the aim of allowing the data to guide coding rather than impose a complete coding scheme.

To ensure that the coding of the themes are somewhat in agreement by all members, the team members had to work individually on the same transcript, individually code it as per agreed themes and then inter-coder consensus had to be reached by team (both etic and emic) members. Expert THPs as members of the research team had to check and 
agree on the coded data by using their knowledge in the field. To ensure data quality, one expert THP member coded the original transcripts in its original indigenous language. This ensured that the translated and original transcripts receive equal rigour of coding and that themes from both transcripts are similar and if not, rigorous exercise was undertaken to establish where a challenge could have been for instance translation or researcher bias and any other attributes that could have influenced the difference in the themes. Therefore as a methodological issue in cross-cultural research, this assisted in ensuring that the message and richness of the text was not lost in translation.

\section{Discussion}

The involvement of indigenous people and/or the custodians of the knowledge sort in research are vital. The power and power relationships during the research are some of the nuances that that seasoned researchers should be sensitive towards. In the western research theory, the researcher has the power and has the question that the researcher wants to answer. Thus, they draw up protocols to understand the phenomenon that they do not know or want to have deeper insight.

In most cases the research engagements tends to leave the participants outside; they are not consulted for instance about the approach and the logic of the researcher's question. Pilot studies are conducted in most cases and are paramount to ascertain whether the research and most importantly the research questions are credible. They are an important research exercise in terms of a research protocol for instance to to check whether the questions ask what they intended to ask as teased by the puzzle or the urge of the researcher's interest in the question. In cross-cultural research this potentially raises a methodological question and thus the credibility of the findings.

A sojourner does not necessarily have the intricate knowledge of the emics of the phenomenon under study. In the cross-cultural study the researchers have the interest in the phenomenon under study. However, the deeper understanding of the phenomenon might require the insider, thus the involvement of the indigenous and/or custodian of the knowledge in cross-cultural studies - as experts, advisors and mentors open up and might strengthen the credibility of the study.

Cross-cultural research as a qualitative inquiry requires proper planning and putting necessary research mechanisms in place before the final stages of starting with the research. It is important, therefore, that the involvement of the indigenous experts and/or custodians of the knowledge under study, be involved in the naming, planning, execution and finalisation of the research. Their role among others includes checking that the research language is appropriate in their field; question protocols are not only appropriate but do they cover what the research intends to find out; the time proposed to conduct research. Also indicate to the research team any other issues that could have been overlooked.

In this study, expert THPs were consulted and they participated in the conceptualisation of the study including the research programme. This was important because their involvement highlighted blind spots that academic and/or western theory researchers could have overlooked. For instance, the expert THPs in this study advised that since THPs guard their knowledge and like in other indigenous cross-cultural research, it will be of benefit to the study to involve and train THPs as moderators and interviewers. This was so because, despite the explanations that the study was not about their THP medicinal knowledge, there was discomfort when non-THPs were even discussing this with them. Thus, focus groups and interviews conducted by one of their own, opened up the process and non-THPs had to distance themselves and check whether the protocol were followed as agreed. This methodological consideration is important for further researches because it allows the sojourner an opportunity to learn, observe and gather richer field notes that will enrich the data during analysis and ultimately the findings and recommendations from the study.

The role of the expert THPs also became profound during the analysis and the interpretation of the data collected. In this study, to attempt to maximise the rich data, expert THPs analysed data in their indigenous languages and compared it with the data that was translated. This exercise ensured that cross-cultural nuances that, for instance can be lost in translations are preserved and where they were lost in meaning, were restored, therefore further authenticating and validating data and the findings. Recommendations from such are richer, grounded and more practical.

\section{Conclusion}

Cross-cultural qualitative inquiry demands of the researcher to be sensitive and honest about the phenomena under study. It is thus important that those conducting cross-cultural studies including therapists in cross-cultural psychology should define their position clearly upfront. As noted, culture is explained differently and thus paramount in research to 
demarcate the position of the research and the researcher. The etics or the outside positioning in cross-cultural research indicates making use of the pre-established categories for organising and interpreting data rather than categories recognised within the culture being studied. Therefore to maximise data collection, analysis and interpretation, this study employed the emics of cross-cultural research by involving the THPs as experts, advisors and mentors so that the rich data can be elicited and analysed.

\section{References}

Broad Reach Health Care, Tabane, R., Mbele-Khama, S. and Dlamini, N. (2012). An exploratory study of how Traditional Health Practices (THP) in South Africa communicate the concepts of disease risk and prevention to their patients. REPORT.

Kagitçibaşi, Ç. and Berry, J. W. (1989). Cross-cultural research: current research trends. Annual Review Psychology. (30), 493-531.

Lomawaima, K. T. (2000). Tribal sovereigns: Reframing research in American Indian education. Harvard Educational Review, 70(1), 121.

Mihesuah, D. A. (2003). Indigenous American women: Decolonization, empowerment, activism. Lincoln, NE: Bison Books.

Mihesuah, D. A., \& Wilson, A. C. (2004). Indigenizing the academy: Transforming scholarship and empowering communities. Lincoln, NE: Bison Books.

Mutua, K., \& Swadener, B. B. (Eds.) (2004). Decolonizing research in cross-cultural contexts: Critical personal narratives. Albany, NY: State University of New York Press.

Pope-Davis, D. B., Toporek, R. L., Ortega-Villalobos, L., Ligiéro D. P., Brittan-Powell, C. S.

Liu, W. M., Bashshur, M. R., Codrington, J. N. and Liang, C. T. (2002). Client perspectives of multicultural counseling competence: A qualitative examination. The Counseling Psychologist (30), 355-393.

Smith, L. T. (1999). Decolonising methodologies: Research and indigenous peoples. London and Dunedin: Zed Books and University of Otago Press.

Swisher, K. G. (1998). Why Indian people should be the ones to write about Indian education. In D. Mihesuah (ed.), Natives and academics: Researching and writing about American Indians (pp. 190-199). Lincoln: University of Nebraska Press.

Traditional Health Practitioners Act 22 of 2007. Pretoria: Government Printers.

Webster, J. P. and John, T.A. (2010). Preserving a space for cross-cultural collaborations: an account of insider/ outsider issues. Ethnography and Education. 5(2), 175-19.

Wilson, A. C. (2004). Reclaiming our humanity: Decolonizing and recovery of indigenous knowledge. In D. Mihesuah \& A. C. Wilson (eds.), Indigenizing the academy: Transforming scholarship and empowering communities (pp. 69-87). Lincoln: University of Nebraska Press.

Wilson, S. (2008). Research is ceremony: Indigenous research methods. Halifax, UK: Fernwood Publishing.

Égisdóttir, S, Gerstein, L. H. and Çinarbaş, D. C. (2008). Methodological Issues in cross-cultural counseling research: Equivalence, Bias and Translations. The counseling psychologist. 36 (2), 188-219. 